\title{
A ARTICULAÇÃO DO POLÍTICO E DO RELIGIOSO NAS DEMOCRACIAS CONTEMPORÂNEAS: UM DIÁLOGO COM LUCA DIOTALLEVI ${ }^{1}$
}

Philippe Portier ${ }^{2}$

A sociologia política do religioso tem desenvolvido, ao longo dos anos, uma série de pesquisas importantes sobre o tema dos regimes de regulação da crença nos países ocidentais. O belo texto de Luca Diotallevi inscreve-se nesse campo de estudos com o objetivo de repensar sob nova perspectiva as teses habitualmente defendidas sobre o assunto.

Em seu ponto de partida, o autor traz uma análise dos grandes tratados da produção científica sobre o assunto. Para o sociólogo italiano, ela se articula globalmente em torno de dois pontos-chave. Ela assinala, por um lado, um fenômeno de convergência: fixados antes nas combinaçôes singulares, produtos eles mesmos de processos diversificados de nation-building, os sistemas de secularismo teriam conhecido, ao longo das últimas décadas, uma reaproximação de seus modelos de organização, na qual a maior parte adotou um sistema de "separação moderada". A produção científica reconhece, por outro lado, um fenômeno de resistência. Dois grandes países, os Estados Unidos e a França, permanceram, por sua vez, na dependência de seu modelo original de "separação radical", proibindo, segundo o axioma colocado no momento de sua entrada na modernidade, qualquer cooperação entre a instituição política e a instituição religiosa.

Nenhuma dessas conclusões, no entanto, foi convincente para Luca Diotallevi. O conceito de "separação moderada" agrega regimes de fato muito diferentes, que não desenvolvem todos o mesmo tipo de parceria entre

1 Tradução: Fernanda Heberle.

2 Diretor do Groupe Societé, Religions, Laïcités (GSRL) pertencente ao Centre National de la Recherche Scientifique (CNRS) e à École Pratique des Hautes Études (EPHE). Contato: philippe.portier@gsrl.cnrs.fr

Debates do NER, Porto Alegre, ano i6, N. 27, P. 85-96, JAn./Jun. 2015 
Estados e Igrejas. O mesmo acontece com o conceito de "separação radical", que erroneamente assimila o sistema francês e o sistema americano de secularismo, ainda que eles não agenciem de maneira idêntica a relação entre privado e público. No fundo, as críticas conectam-se: o sociólogo italiano critica os modelos de análise em seu caráter geral e, portanto, redutor: eles não levam em conta, diz ele, a pluralidade de experiências contemporâneas de gestão pública do crer, a despeito do processo de globalização.

A crítica clama por um programa. Luca Diotallevi dedica-se a retomar os diferentes modelos nacionais a fim de captar a sua idiossincrasia. Seu texto detém-se especialmente sobre os casos americano e francês: ele pretende mostrar que a «separação radical» entre o Estado e as forças religiosas é muito menos afirmada nos Estados Unidos do que na França. Fortemente argumentada, a tese é convincente. No entanto, ele deixa permanecer alguns pontos cegos, especialmente sobre a gênese e a plasticidade dos modos nacionais de articulação da relação Igrejas/Estado.

\section{ZONAS DE CONVERGÊNCIA}

A zona ocidental do mundo é caracterizada pelo que Alfred Stepan chama de "twin toleration"3 (grifo nosso), ela mesma associada ao processo de secularização (entendido aqui como um processo de perda de relevância social das afirmações de natureza religiosa). Por um lado, a instituição política, agora dissociada da vontade de Deus, não intervém mais no domínio da salvação: ela deixa cada um com suas próprias escolhas, e até mesmo com a sua liberdade de não acreditar. Por outro lado, a instituição religiosa, se intervém na esfera da disputa pública, já não determina a lei coletiva: é apenas uma voz entre outras vozes igualmente legítimas como base para a decisão política.

3 STEPAN, Alfred. Religion, Democracy, and the "Twin Tolerations". Journal of Democracy, v. 11, p. 37-57, out. 2000.

Debates do NER, Porto Alegre, ANo I6, N. 27, P. 85-96, JAN./Jun. 2015 
Luca Diotallevi propõe, em primeiro lugar, uma análise do modo de geração desse secularismo jurídico. Seu esquema, que deve muito à obra de Niklas Luhmann, baseia-se no paradigma da diferenciação social. $\mathrm{O}$ princípio é conhecido: a fim de reduzir a "complexidade" do mundo, todos os humanos em conjunto organizam sua existência por meio da definição de esferas de atividades, todos eles postos por um sistema axiológico (sinn) e separados uns dos outros por fronteiras evolutivas. No entanto, releva o sociólogo italiano, este acordo tem evoluído ao longo da história. A era pré-moderna confronta-nos com uma diferenciação unificada: as funções políticas, econômicas, científicas, artísticas da sociedade são colocados sob tutela da norma religiosa. Hermann Tyrell descreve, assim, a articulação religião/política sustentada por esse modelo:

Com a fórmula do 'coge intrare' (ou 'compelle intrare'), forjada por Santo Agostinho, o convite, por assim dizer, dirigido ao Estado, impõe, se necessário pela força (por meios especificamente estatais) o pertencimento dos sujeitos à Igreja, de modo que 'grupo político' e 'grupo hierocrático' acabam por se sobrepor, 'coïncider', como disse Weber, em termos de seu impacto social e da sua esfera de dominação ${ }^{4}$.

A era moderna é construída, em vez disso, sob uma diferenciação pluralizada. Os subsistemas autonomizam-se em relação à função religiosa e definem seu próprio "meio de comunicação". Assim se dá com a esfera política: ela afirma, contudo, uma soberania - o que a leva a rejeitar outros princípios normativos que não aqueles que ela dá a si mesma. Para Luca Diotallevi (2015), a liberdade religiosa do sujeito está ligada com a autonomia jurídica do poder. Isso ocorre porque as sociedades se constroem independentemente de uma norma englobante em que cada um pode decidir suas próprias opções, incluindo as da esfera espiritual, sem ser limitado por um poder político submisso à ordem religiosa: a diferenciação funcional

4 TYRELL, Hartmann. Religion und Politik: Max Weber und Émile Durkheim. In: BIENFAIT, A. (Ed.). Religionen verstehen. Wiesbaden: Verlag für Sozialwissenschaften, 2011, p. 61. 
produz os direitos. Sem dúvida, as relações institucionalizadas podem se manter entre as duas instâncias, como tem acontecido na maioria dos países europeus. Elas não são da mesma natureza da sociedade pré-moderna, uma vez que a lei política não depende mais da lei canônica.

Vamos nos tornar voluntários desse esquema analítico. No que diz respeito à relação de consecução postulada por Luca Diotallevi entre soberania política e liberdade religiosa, talvez devamos acrescentar esta advertência: a soberania política é uma condição necessária da liberdade religiosa; não é uma condição suficiente. Claude Lefort e Emilio Gentile mostraram em seus respectivos trabalhos sobre o comunismo e o fascismo, que a política poderia, mesmo num regime de modernidade, transformar-se em religião e abolir repentinamente a possibilidade de liberdade de consciência. A teoria dos sistemas sociais não pode, nesse caso, fazer a economia da teoria dos regimes políticos: para que a liberdade seja protegida, é necessário que, por meio de uma série de dispositivos técnicos, o sistema de direito estabeleça o poder político longe de qualquer concepção particular de bem (princípio da neutralidade), aceitando, na ordem que rege, todas as expressões religiosas e convicções, desde que, é claro, elas não prejudiquem outras (princípio da pluralidade).

O sociólogo italiano propõe, em segundo lugar, uma análise do modo de diversificação do secularismo jurídico. A modernidade não engendrou um modelo único de separação do político e do religioso: ela conhece "diferentes variantes da diferenciação institucional." O texto cita o modelo inglês; faz também referência aos sistemas escandinavos de confissão. Ele para, contudo, diante dos casos americano e francês. Muitos autores os englobam voluntariamente, por assim dizer, na mesma categoria da "separação estrita". Um sociólogo francês escreveu recentemente nesse sentido: "A França e os Estados Unidos aparecem como campeões da institucionalização da laicidade, [...], sendo guardiōes de um quadro secular estabelecido precoce, durável e solidamente."5

5 FROIDEVAUX, Camille. Religion et politique dans les sociétés sécularisées. Critique internationale, Paris, n. 44, p. 15, juil./sept. 2009.

Debates do NER, Porto Alegre, ano i6, N. 27, P. 85-96, JAn./Jun. 2015 
Luca Diotallevi defende uma outra tese. Ele acredita, por sua vez, que se os dois países usam a mesma palavra, eles não cultivam de fato a mesma prática de separação. Na América, a separação é flexível e define um regime de "liberdade religiosa": para além da liberdade de religião que funda, aqui, a liberdade de consciência ${ }^{6}$, o "espaço público" é aberto à intervenção dos "discursos" e dos "atores" religiosos. A França apresenta traços simetricamente opostos: ela fez da liberdade de religião uma consequência da liberdade de consciência, e, desde a lei de separação, de nove de dezembro de 1905, fechou a esfera do Estado a qualquer interferência do poder eclesiástico. Ela apresenta um "regime de laicidade".

A descrição estende-se para um esquema explicativo. À maneira de um Pierre Birnbaum, na França, ou de um Mathias Koenig, na Alemanha, Luca Diotallevi coloca a variável estatal no primeiro plano de sua demonstração. Os EUA, afirma ele, seria uma sociedade sem estado (Stateless Society). O Estado é baixo. Ele não tem nenhuma vocação para ser, nas palavras de Émile Durkheim, o "reitor" da sociedade. Com o apoio de um sistema judicial independente do poder político, ele se contenta em articular os incontáveis pluralismos, sem reduzi-los a um. Esse esquema é ainda mais enraizado que o modelo de agenciamento do político de tipo federal. Nessa configuração, as fronteiras do político são necessariamente muito porosas e, nesse sentido, suscetíveis de se abrir, mais facilmente do que em outros lugares, ao religioso. A França confronta-nos ao contrário, especialmente a partir da Terceira República (1880), a um modelo de Estado forte (Strong State). O poder é realizado aqui visando à sociedade. À maneira da Igreja Católica, cujos traços ele retoma mimeticamente, contendo em si os arquivos da razão universal, ele pretende construir do alto, sob o fundamento de sua lei e de sua escola, um mundo do público em geral, no qual cada um poderá, amanhã, dissociando-se dos arcaísmos religiosos, ascender à "maioria". Exceto

6 Puisque la religion est ce qui se vit en conscience. Ver FORST, Rainer. Toleranz im Konflikt: Geschichte, Gehalt und Gegenwart eines umstrittenen Begriffs. Francfortsur-le-Main: Suhrkamp, 2003.

Debates do NER, Porto Alegre, ano i6, N. 27, P. 85-96, JAn./Jun. 2015 
entre alguns Republicanos (minoritários), não se trata, naturalmente, de que o Estado falhe em eliminar o religioso do horizonte humano. Significa, antes, contê-los apenas no espaço privado dos sujeitos.

Nós poderíamos ilustrar a tese de Luca Diotallevi por meio de dois exemplos. $\mathrm{O}$ primeiro diz respeito à questão do uso de símbolos religiosos nas escolas públicas. A França o tornou ilegal pela lei de quinze de março de 2004, invocando, ao mesmo tempo, a necessidade de promover a emancipação das meninas jovens em relação a uma prescrição confessional, e o objetivo de evitar que a escola da República se torne um espaço de convulsão de comunidades justapostas. Os Estados Unidos, em seu conjunto, não entenderam essa lei, fato relacionado a um tipo de universalismo estatal que eles não praticam. Eles, por sua vez, privilegiam o seu "princípio da tolerância", aceitando, sem qualquer dificuldade, o uso de símbolos religiosos nas escolas: o Estado aqui não deseja produzir a unidade. $\mathrm{O}$ seu papel é muito mais o de articular as diferenças.

O segundo exemplo diz respeito à questão do modo de constituição da religião civil. Na França, de fato, a relação entre religião civil nacional laica e o cristianismo, em particular a Igreja Católica, são quebradas depois de 1880, uma vez que o catolicismo é banido da esfera pública, o Estado-Nação, na representação que ele faz de si mesmo, é levado a renunciar a qualquer utilização do repertório de símbolos cristãos tradicionais. Não é assim na América. Sem se associar a denominações particulares, a religião civil, aqui, deve em muito a uma espiritualidade deísta, na qual todos, sem nenhum conflito necessário com a sua própria religião-Igreja, podem ser reconhecidos.

\section{PONTOS DE DISCUSSÃO}

O texto de Luca Diotallevi oferece um modelo de análise de primeira importância. No entanto, pode provocar discussão. Sem dúvida esta é a falha de sua qualidade: como em Luhmann, o modelo é acompanhado por um déficit de historicidade, devido, provavelmente, à subvalorização da 
dinâmica da subjetividade, tal como indicado por Jürgen Habermas em sua crítica ao sistemismo. Gostaríamos aqui de tentar restabelecer a diacronia na sincronia da proposta, interrogando sucessivamente, como mencionado anteriormente, a gênese e o desenvolvimento dos sistemas ocidentais de regulação de crença.

A primeira pergunta é sobre a constituição dos modelos de relação Igrejas/Estado. Não está claro, na proposta de Luca Diotallevi, por que os franceses têm defendido a hegemonia do político e os americanos, a abertura religiosa. A resposta está no processo de construção do Estado-Nação. Duas características principais distinguem os dois países. Em primeiro lugar, suas trajetórias políticas. Na França, desde a época barroca, para reduzir as fraturas decorrentes das guerras religiosas, o Estado coloca-se acima das sociedades locais. Instala-se em toda parte nas províncias de administradores ligados ao centro parisiense, e impóe às periferias, contra a tradição estabelecida, a lei monarca.

Quanto à gestão da consciência pública, através das regras do gallicanismo, ele submete a Igreja Católica ao seu controle, defendendo, é verdade, a sua hegemonia formal. Aqui, a "dinâmica do Ocidente", descrita por Norbert Elias, apresenta-se por completo: enfrentando uma forte resistência das unidades locais, o poder governamental solidifica-se em torno de um governo central poderoso. Essa é a premissa de um pensamento de unidade do Estado, que a Revolução de 1789, o Império Napoleônico, e também a República, vão fortalecer ainda mais. $\mathrm{O}$ processo de nation-building não foi o mesmo nos Estados Unidos, onde o Estado foi construído por um remonte confederal (inicialmente) sem configuração autoritária da ligação política.

As estruturas religiosas dos dois países tiveram um peso ainda maior. $\mathrm{Na}$ França, o catolicismo é a força religiosa dominante, se não hegemônica. No entanto, isso é problemático. À época, o catolicismo opôs-se, de fato, às grandes ideias da modernidade emergente. No momento da redação da Concordata (1801-1802), Portalis, o grande jurista de Napoleão I, previu que a Igreja abdicaria de suas nostalgias do Antigo Regime para se colocar plena- 
mente no mundo do Iluminismo. Não foi isso o que aconteceu, no entanto. $\mathrm{Na}$ medida em que o século XIX avançava, os fiéis de Roma mantêm-se numa intransigência cada vez mais acentuada, da qual o Syllabus de 1864 fornece uma ilustração clara, condenando a proposição segundo a qual "[...] o pontífice romano pode se reconciliar com a liberdade, o progresso, a nova civilização", e cultivando o projeto de substituir qualquer lei sob o governo da norma divina. Os Estados Unidos apresentam, por sua vez, uma configuração totalmente diferente. Aqui é o protestantismo, conformado por muitas denominações, que domina a cena religiosa, e cuja inclinação, inversa àquela seguida pelo catolicismo, é acompanhar a modernidade, de tal forma que muitos de seus líderes não hesitam em defender a ideia mesmo de separação após as elaborações de Roger Williams, no Estado de Rhode Island, no século XVII 7 . Isso traz-nos de volta à tipologia de Luca Diotallevi. Na França, as condiçôes eram propícias para o estabelecimento

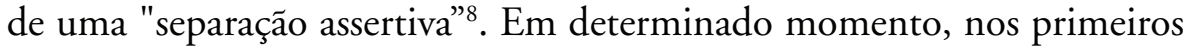
anos do século XIX, pensou-se poder associar a ideia de Estado forte àquela de religião pública. Era a aposta dos promotores do pacto concordatário. A retração da Igreja sob um forte tradicionalismo impediu que esse tipo de confessionalismo moderno, que vemos ainda funcionando em alguns países escandinavos ${ }^{9}$, pudesse perseverar-se em si mesmo. O caso americano, organizado, por sua vez, em torno de uma "separação passiva" ${ }^{10}$, procede

7 Sobre esses pontos, ver MARTIN, David. Religion and Power: No Logos Without Mythos. London: Ashgate, 2014. Ver também PORTIER, Philippe. Modernités plurielles? Une analyse longitudinale des régimes de regulation du croire dans les démocraties stabilisées. In: MILOT, Michelle; PORTIER, Philippe; WILLAIME, Jean-Paul. Pluralisme religieux et citoyenneté. Rennes: PUR, 2009, p. 220-255.

8 KURU, Ahmet. Secularism and State Policies toward Religion: The United States, France, and Turkey. Cambridge, UK: Cambridge University Press, 2009.

9 Dans un contexte religieusement différent, où la religion dominante est un luthéranisme très adaptable à la modernité.

${ }^{10}$ KURU, Ahmet. ibid.

Debates do NER, Porto Alegre, ano I6, N. 27, P. 85-96, JAN./Jun. 2015 
de um outro contexto. Se os significados religiosos ${ }^{11}$ foram capazes de se misturar, no coração mesmo do espaço público, aos significados políticos, é porque o Estado, aqui desprovido de qualquer propósito magisterial, não teve de lidar com uma religiáo que contestou sua autonomia. Uma pergunta permanece ainda sem solução: por que os EUA quiseram impedir o establishment, como foi o caso em outros países, a exemplo da Inglaterra, também favoráveis ao ethos religioso? Dá-se precisamente aqui, em um contexto marcado por um vasto pluralismo religioso, para permitir que indivíduos crentes pudessem cultivar seu pertencimento religioso, sem ser forçado ou influenciado pela escolha do Estado em favor de uma denominação em particular. Esses são originalmente, portanto, dois modelos distintos de separação que se confrontam: na França, ele é projetado com a intenção de roubar o Estado da empresa do religioso, considerada como potencialmente draconiana; nos Estados Unidos, ele é construído com o objetivo de conferir à sociedade civil em geral a mais ampla expressão religiosa, vista aqui como substancialmente civilizadora.

A segunda questão, mais central, refere-se à transformação de modelos de regulação da crença. O texto de Luca Diotallevi tende a congelá-los em uma estabilidade a-histórica. No entanto, a história confronta-nos com os padrões de mudança. Os Estados Unidos, por exemplo, experimentaram uma inflexão poderosa suficientemente "secular" nos anos 1960-1970, sob o efeito de um fortalecimento do Estado engajado desde o New Deal, mas também um processo de liberalização da opinião pública. A Suprema Corte produziu naquele momento toda uma jurisprudência que veio a marcar mais rigorosamente a separação entre o político e o religioso. Algumas decisões judiciais proibiram os momentos obrigatórios de oração dentro dos complexos escolares - como a decisão Engel vs. Vitale, em 1962, confirmada, em 2000, pela decisão Santa Fé Distrito Escolar Independente vs. Doe. Ainda a decisão

${ }^{11}$ Prenons soin de rappeler que si ce système accepte que des choix individuels se manifestent dans l'espace d'Etat ou l'expression d'une religiosité diffuse, il interdit toute reconnaissance officielle d'un confession particulière.

Debates do NER, Porto Alegre, ano i6, N. 27, P. 85-96, JAn./Jun. 2015 
Lemon vs. Kurtzman, em 1971, na qual, aprofundando os argumentos do caso Everson vs. Board of Education, de 1947, proibiu-se qualquer possibilidade de financiar atividades escolares confessionais. $\mathrm{O}$ que permitiu a uma jurista francesa, Elizabeth Zoller, dizer que os Estados Unidos haviam instituído um sistema "tão exigente quanto a laicidade francesa"12.

É verdade, no entanto, para ir na direção de Luca Diotallevi, que o período recente, sob a pressão da dessecularização descrita por Peter Berger, em certos pontos, (pensemos nas Faith Based Initiatives defendidas por Bush e por Obama) renovou o espírito philoclerical do período anterior. A França evoluiu também, graças à sua adesão em 1970 aos mecanismos do Estado de Direito (com um aumento do poder do sistema judiciário), ela mesma ligada a um questionamento do republicanismo excessivo. Dali em diante, o Estado financia os cultos, confia as missões de mediação e de especialidade às Igrejas, abre suas escolas para o ensino das fés religiosas, admite praças confessionais nos cemitérios comunais, de modo que podemos, sem dúvida, agora subsumir o modelo francês na categoria de "separatismo moderado".

O que pensar dessa categoria, na qual, hoje em dia, os comentaristas inserem a maioria dos Estados? Para Luca Diotallevi, essa categoria é excessivamente ampla. Segundo ele, ela ignora o fato de que os estados que a instituíram não têm a mesma public agency, nem a mesma relação com a sociedade civil (ele opõe, a partir deste ponto de vista, o modelo "corporativista" e o modelo "associativista"). O sociólogo italiano toca apenas em uma parte. A Alemanha, por exemplo, com o seu sistema de Estado subsidiário, não é a Inglaterra, com seu regime de Estado liberal. Ao mesmo tempo, os pontos de convergência ocorrem: sua inscrição em um contexto semelhante, marcado pela imigração, pela perda de poder do Estado, pela afirmação de reivindicações religiosas, pelos regimes ocidentais em tudo estabelecidos sem abolir todas as características de seu sistema anterior,

12 ZOLLER, Elizabeth. La Lä̈cité américaine. Paris: Dalloz, 2005. p. 17. 
em esquema de pluralismo ordenado (ou "neocorporatismo") baseado nas interações mais pesadas entre o Estado e as Igrejas. Sem dúvida, devemos deixar o nosso "nacionalismo metodológico" e concordar que a segunda modernidade, com a entrada no universo da mundialização, tem, no Ocidente, um efeito dissolvente sobre os modelos de secularismo nascidos na primeira modernidade ${ }^{13}$.

13 PORTIER, Philippe. Les laïcités à l'épreuve de la deuxième modernité. In: BAUBÉROT, Jean; MILOT, Micheline; PORTIER, Philippe. Lä̈cité, Lä̈cités. Paris: Editions de la Maison des Sciences de l'Homme, 2014.

Debates do NER, Porto Alegre, ano i6, N. 27, P. 85-96, Jan./Jun. 2015 


\section{REFERENCIAS}

FORST, Rainer. Toleranz im Konflikt: Geschichte, Gehalt und Gegenwart eines umstrittenen Begriffs. Francfort-sur-le-Main: Suhrkamp, 2003.

FROIDEVAUX, Camille. Religion et politique dans les societés sécularisées. Critique internationale, Paris, n. 44, p. 15, juil./sept. 2009.

KURU, Ahmet. Secularism and State Policies Toward Religion: The United States, France, and Turkey. Cambridge, UK: Cambridge University Press, 2009.

MARTIN, David. Religion and Power: No Logos Without Mythos. London: Ashgate, 2014.

PORTIER, Philippe. Modernités plurielles? Une analyse longitudinale des régimes de régulation du croire dans les démocraties stabilisées. In: MILOT, Micheline; PORTIER, Philippe; WILLAIME, Jean-Paul. Pluralisme religieux et citoyenneté. Rennes: PUR, 2009. p. 220-255.

Les laïcités à l'épreuve de la deuxième modernité. In: BAUBÉROT, Jean; MILOT, Micheline; PORTIER, Philippe. Lä̈cité, Lä̈cités. Paris: Editions de la Maison des Sciences de l'Homme, 2014.

STEPAN, Alfred. Religion, Democracy, and the "Twin Tolerations". Journal of Democracy, v. 11, p. 37-57, oct. 2000.

TYRELL, Hartmann. Religion und Politik: Max Weber und Émile Durkheim. In: BIENFAIT, A. Religionen verstehen. Wiesbaden: Verlag für Sozialwissenschaften, 2011, p. 61.

ZOLLER, Elizabeth. La Laïcité américaine. Paris: Dalloz, 2005, p. 17.

Recebido em: 02/07/2014

Aprovado em: 05/08/2014

Debates do NER, Porto Alegre, ANo I6, N. 27, P. 85-96, JAN./Jun. 2015 